\title{
Escolarização e leitura para crianças no Brasil no início da República
}

\author{
Schooling and reading for children in Brazil at \\ Republicas' beginning
}

\section{La scolarisation et la lecture pour les enfants au Brésil au début de la République}

\author{
Roseli Maria Rosa de ALMEIDA \\ Ana Lucia ESPÍNDOLA
}

\section{RESUMO}

No artigo em questão, faremos algumas reflexões sobre o processo de escolarização no Brasil do início da Repúblicà, através da expansão da escola primária. Buscamos estabelecer relações entre as questões relativas à expansão dos livros e a ampliação da publicação da literatura infantil no país.

Palavras-chave: escolarização, escola primária, leitura, livros para crianças.

\section{ABSTRACT}

This paper presents some reflections about Brazil's schooling process at Republica's beginning with the primary school expansion. It seeks to establish a relationship between the book expansion and the increase of children's literature publication in the country.

Index terms: schooling, primary school, reading, children's books.

\section{RESUME}

Cette étude présente quelques remarques sur le processus de scolarisation par la diffusion de l'école primaire au Brésil au début de la République. On cherche établir des rapports entre la diffusion des livres et l'augmentation des publications de la littérature enfantine du pays.

Mots clés: scolarisation; école primaire; lecture, livres pour enfant. 


\section{Introdução}

No artigo em questão pretendemos realizar uma discussão sobre a escolarização dos saberes elementares a partir de Hébrard (1990), da escolarização no Brasil no início da República, a partir dos trabalhos de Souza (2004) e Nagle (2001), observando a relação existente entre a ampliação da necessidade de escolarização da população brasileira, a expansão da escola primária e a ampliação da indústria de livros para crianças, utilizando os trabalhos de Lajolo e Zilberman (1985, 1996, 2002); Lajolo (2006) e de Feijó (2005).

Para refletir sobre os pontos acima mencionados, temos ao longo de nosso estudo tentado encontrar respostas para questões a respeito do surgimento da "escolarização" enquanto necessidade: será que podemos resgatar um momento na história em que saberes como ler, escrever e contar se tornaram tão necessários ao homem e vinculados a uma instituição a qual caberia transmiti-los?

\section{Escolarização dos saberes elementares}

Com essas indagações nos reportamos aos estudos de Hébrard (1990) sobre a escolarização dos saberes elementares na época moderna, onde o mesmo investiga a construção da escolarização desses saberes, a partir da França e nos fornece elementos para discussão. É interessante considerar de início, que os saberes elementares (ler-escrever- contar) nem sempre estiveram vinculados ao processo de escolarização. Assim, Hébrard (1999, p. 37) adverte que:

Historicamente a escola não pode ser considerada o único lugar-nem o lugar preponderante - onde se constroem e transmitem os equipamentos intelectuais de uma sociedade. Ela desempenha um papel (menos 
ou mais) importante na sua definição, em particular quando enuncia as normas legítimas do seu uso.

Para o autor (1999, p. 37) "a alfabetização universal dos cristãos foi considerada necessária após o Concílio de Trento para transmitir a ciência da salvação". Até a Revolução, na França, nos lembra Hébrard (1990, p. 40), "aprendia-se a ler, antes de aprender a escrever, depois, desenhar os números". Por isso mesmo a importância da trilogia em questão foi sendo construída historicamente, nos conflitos de classes com diferentes interesses, onde podemos observar grupos divergentes quanto à "socialização de determinados saberes". Assim com a necessidade de escolarização dos cristãos (1990, p. 37):

A Igreja Católica deu, então, as escolas paroquiais e às instituições escolares, fundadas pelas novas congregações docentes, um impulso tal que é impossível reconstruir uma história da cultura escrita sem encarar as modalidades de sua escolarização.

Os movimentos sociais de diferentes grupos impuseram "necessidades" diversas em relação à leitura, à escrita e ao cálculo em diferentes momentos da história. Hébrard (1990) nos lembra que antes de serem disciplinas escolares, o ler-escrever e contar eram atividades de profissionais, que trabalhavam com o latim, língua que exigia uma longa familiaridade. No século XVI, com a criação os colégios criados para formação das elites há uma incorporação do ensino da língua latina nos currículos.

A responsabilidade dos saberes elementares era da família, uma vez que "os alunos que chegavam ao sexto grau sabiam geralmente ler e manejar a pena" (HÉBRARD, 1990, p. 42). Sucessivamente vão se modificando os modelos de aprendizagens desses primeiros saberes: no século XVII ler para poder instruir o cristão, sendo o catecismo o livro de 
leitura; No século XVIII, uma escola que integraria o ler, já trabalhado antes com o latim, o escrever e o contar: proposta por Jean-Baptiste de La Salle e que proporia a leitura em francês. Junto com as mudanças, a ampliação da escolarização, os “níveis de aula", as classes (HÉBRARD, 1990, p.46).

Um aspecto que devemos ponderar ao pensarmos os saberes elementares é que os mesmos passam a serem considerados como prérequisitos de outras aprendizagens, de acordo com Hébrard (1990, p. 66), e, além disso, não era somente a escola a responsável pela transmissão desses saberes em determinados momentos da história, pois "os locais das primeiras aprendizagens são tanto não-escolares quanto escolares e, elas são tratadas muito diversamente de acordo com as trajetórias futuras das crianças. Assim, um ponto a ser pensado é "como essa trilogia, do nosso ponto de vista, tão natural, é produzida na e pela escolarização (HÉBRARD, 1990, p.67).

A escola torna-se, no século XVIII, o lugar dessas primeiras aprendizagens, no entanto, não sem as contradições que cercam a difusão desses saberes. Para Hébrard (1990, p. 69) vários segmentos estão interessados na difusão desses saberes, tendo em vista que:

Precisamos, pois examinar igualmente com atenção esse momento em que as Igrejas consideram necessário ligar a formação religiosa das "crianças e dos rudes" não mais a prédica e aos rituais do ano litúrgico, mas a uma alfabetização mais ou menos generalizada.

Essas contradições são evidenciadas pelo historiador, ao mostrar a relação que se estabelece entre uma "ruptura" (que mais figura como uma necessária adequação) de tradição cristã oral e gestual, passando ao que chamou de ciência da "salvação", onde "o livro é a manifestação mais concreta e a leitura a forma privilegiada de apropriação" (HÉBRARD, 1990, 
p. 69). O livro, objeto de materialização da leitura, não por acaso passará a ser divulgado ou ocultado, dependendo dos interesses de classes.

Assim, percebe-se que a "necessária" escolarização dos saberes elementares constrói-se a partir de interesses distintos e conflituosos entre segmentos da Igreja e outros grupos sociais. Quais intenções tinham esses segmentos com a expansão da escolarização e conseqüentemente com a difusão desses saberes elementares?

Muitos interesses estão ocultados no processo de escolarização. Já no século XIX, em estudos de cem anos de leitura na França- 1880 a 1980, Chartier \& Hébrard (1995) identificam discursos que aparentemente defendiam posições contrárias em relação á leitura, mas que progressivamente constituir-se-ão em um discurso unificado, onde a leitura passa a ter valor universal.

O aluno, o indivíduo, precisa converter-se no leitor e o local dessas aprendizagens seria a escola. São construídas e ampliadas a partir de então duas categorias fundamentais no processo de mudança na sociedade moderna: o tempo e o espaço escolar. As tarefas antes designadas a outros setores da sociedade, como a família e a Igreja, passam a ser da escola, dentro elas a difusão e transmissão dos saberes elementares, que configuraram "imprescindíveis" ao novo homem que se pensa a partir de então.

\section{O Brasil e o processo de escolarização no início do século XX: algumas considerações}

Realizamos essa breve retomada de questões trabalhadas pelo estudioso francês, para considerar nosso ponto de partida em relação à valorização dos saberes elementares, dentre eles, a leitura. A relação da 
escolarização com a expansão da leitura no Brasil parece ter uma ligação bastante propícia, que poderemos observar ao longo deste texto a partir de diferentes personagens, quais sejam: autores, editores, leitores e a escola.

Há de se considerar que até a década de 1920 uma pequena parcela da população brasileira freqüentava a escola e havia uma crença na escolarização como "salvadora da pátria”, como propulsora de grandes saltos no desenvolvimento econômico e social do país, gerando o que Nagle (2001, p. 134) evidenciou:

Diante do fenômeno da liberação institucional, que provoca a abertura de novos caminhos no plano do pensamento e da atuação, é preciso conhecer o sentido da contribuição desse processo civilizatório, tanto sob a forma de padrões de pensamento quanto sob a forma de padrões de realização escolar.

Parece ser marcado um momento de busca por uma escolarização que deveria ser crescente, evidenciando o que autor (NAGLE, 2001, p. 134) vem caracterizar como sentimento de entusiasmo e otimismo pedagógico, caracterizados como sendo:

De um lado, existe a crença de que, pela multiplicação das instituições escolares, da disseminação da educação escolar, será possível incorporar grandes camadas da população na senda do progresso nacional, e colocar o Brasil no caminho das grandes nações do mundo; de outro lado, existe a crença de que determinadas formulações doutrinárias sobre escolarização indicam o caminho para a verdadeira formação do novo homem brasileiro (escolanovismo).

Assim, à educação escolarizada é atribuído um grande potencial, um poder de transformação do país e da sociedade brasileira. Vista como o "motor da história" (NAGLE, 2001, p. 134), evidenciará o aparecimento de 
discussões e reformas constantes no início do século XX, especialmente no que se refere ao ensino primário.

Indagamo-nos: como falar em leitura em um período que uma grande parte da população era analfabeta?

Apesar de somente uma pequena parcela de a população ter acesso à escolarização e o final do século XIX ser marcado pela carência de obras nacionais para literatura infantil e juvenil (embora esta adjetivação da literatura seja questionada por vários autores, entre eles Lajolo e Zilberman; 1985), essa situação vai se alterar substantivamente a partir do início do século XX. A expansão da "necessidade" da escola para a população faz crescer também o interesse em publicar livros para atingir este público, marcando um aumento do interesse pela edição de livros para crianças (no caso da escola, especialmente os didáticos).

Segundo Nagle (2001, p. 149):

Os dados do recenseamento de 1920, as discussões e os estudos resultantes da conferência sobre o ensino primário de 1921 e o constrangimento que dominou o ambiente espiritual em 1922, quando, ao mesmo tempo que se procurava comemorar o centenário da independência, pesava sobre a nação uma quota de $80 \%$ de analfabetos- conforme os cálculos da épocatransformaram o analfabetismo na grande vergonha do século, no máximo ultraje de um povo que vive a querer ingressar na rota da "moderna civilização".

A via encontrada inicialmente para alcançar a melhoria do país pela educação, diz NAGLE (2001, p. 150) "é a alfabetização, tida como o "primeiro passo" necessário da educação primária, e se considerava mais democrático ensinar a ler, escrever e contar a maioria das crianças, do que fornecer uma educação mais ampla, porém, para uma minoria apenas". Aqui nos reportamos novamente ao início deste trabalho, quando nos remetemos 
ao valor que progressivamente a escola e os saberes elementares vão alcançando ao longo da história, na Europa do século XVIII e no Brasil do século XX, o que no Brasil se caracterizará pela "urgência de escolarização da população".

Progressivamente a necessidade de uma escola alfabetizante (NAGLE, 2001, p. 151), "passa a exigência da escola primária integral, considerada a principal instituição formadora do caráter nacional e que, por isso mesmo, deve ter as preferências dos governantes”. Além disso, é repensada a necessidade da educação técnico-profissional, para formação da mão-de-obra, visando o que o autor chamou de tentativa de tornar a civilização brasileira "eminentemente prática, como práticas eram as mais modernas e avançadas civilizações do mundo contemporâneo" (NAGLE, 2001, p. 153).

Assim, são mobilizados esforços no sentido da ampliação da escolarização, especialmente a primária, como forma de reduzir o atraso brasileiro. Estudos da pesquisadora Rosa Fátima de Souza (2004), mostram a implantação e modernização do ensino primário, no Estado de São Paulo, passando a outros Estados, observando-se uma adequação dos métodos, expressos na consideração de que (2004, p. 116): “O estabelecimento de um programa uniforme e de exames padronizados converteu as primeiras aprendizagens e outros saberes em matérias de ensino, e a lógica dos conteúdos passou a presidir a organização da escola".

A partir das influências do pensamento positivista, o Brasil do entusiasmo e do otimismo pedagógico, com a defesa de uma alfabetização em massa, "pretende que a escola brasileira se transforme radicalmente na década de 1920: nos objetivos, conteúdos e função social" (NAGLE, 2001, p. 152). Além disso, 
O movimento que procurou transformar o ensino normal no Brasil, nessa década, resultou ainda, da superestimação da escola primária, pois as discussões, planos e reformas nesse tipo de ensino foram freqüentes, mas com o objetivo de ajustá-lo às novas funções da escola primária (NAGLE, 2001, p. 152).

Explica-nos Souza (2004, p.117) que o tempo passa a ter uma ordenação minuciosa, além de ser exigida uma rígida disciplina e bom comportamento pelos alunos, "verificado pela assiduidade, freqüência, pontualidade, asseio, ordem, obediência, cumprimento dos deveres" Os programas da escola primária passam por várias reformas.

Em todas essas reformulações, as alterações incidiram mais sobre a configuração das matérias (aglutinação de conteúdos e sua distribuição nas séries) e ampliação das indicações metodológicas do que sobre a seleção cultural. Isto significa dizer que, até 1968, se manteve praticamente o mesmo conjunto de matérias estabelecido no final do século XIX (SOUZA, 2004, p. 128).

Apesar dos ideais de valorização da escola primária, como forma de garantir a escolarização de uma grande parte da população que era analfabeta, havia uma precariedade, tanto dos espaços escolares, quanto da adequação dos turnos escolares, favorecendo a criação de turnos emergenciais, além de outras questões que os relatórios da época evidenciam. Enfatiza Souza (2004, p. 124) que:

À falta de vagas-incapacidade do Estado em atender à demanda em idade escolar- somam-se outros problemas: precariedade dos edifícios escolares, alta seletividade do ensino primário, carência de mobiliário e material didático, falta de uniformidade e padronização do ensino, dificuldade do emprego dos métodos modernos de ensino e de cumprimento integral dos programas escolares, dificuldade de provimento de professores nas escolas isoladas, 
baixos salários dos professores e precárias condições de trabalho.

As contradições decorrentes da tentativa de implantação do ensino primário no país mostram-se também no campo do currículo. Dificuldades para cumprimento integral do programa de ensino são evidenciadas pelos estudos de Souza (2004, p. 132), em relatórios de inspetores e diretores de grupos escolares no Brasil. Evidencia a autora que matérias como "leitura, escrita, caligrafia e aritmética, eram consideradas fundamentais" (SOUZA, 2004, p. 132) e outras ficaram em segundo plano, havendo também matérias as quais se dedicava pouco tempo, como: desenho, música, ginástica e trabalhos manuais.

Com relação à leitura, em séries utilizadas até meados do século XX, registram-se a integração entre os textos destinados à leitura pelos alunos com a instrução de moral e cívica, além da prescrição de normas de comportamento, de civismo e de conduta em relação à escola, à família e a sociedade (Cf. SOUZA, 2004). Na literatura infantil, a poesia tem papel importante, no entanto o conteúdo também não foge de certo aspecto moralizante.

Os poemas de Gonçalves Dias, Castro Alves, Casimiro de Abreu, Camões, Fagundes Varella, entre outros punham as crianças com a cultura erudita, mas eram selecionados com uma finalidade formadora muitas vezes de natureza moral e cívica (SOUZA, 2004, p. 133).

É na carência de material didático que os editores brasileiros encontram a possibilidade de expandir negócios via escolarização. Se no século XIX, como destaca Lajolo \& Zilberman (2002, p. 124), a escrita no Brasil seria um "péssimo negócio", fruto de uma imprensa com infraestrutura precária, no século XX será observada uma necessidade de produção de literatura para crianças e a nacionalização da produção de obras 
destinadas ao público adulto, através do investimento de editores nacionais e estrangeiros.

\section{Escolarização, leitura e livros para crianças no Brasil}

As décadas de 1920 e 1930 no Brasil serão marcadas por reivindicações de mudança no campo educacional e partidos políticos, organizações da sociedade civil, intelectuais se voltam para a questão da escolarização da população. A exemplo desses movimentos, Nagle (2001, p. 137) observa suas implicações:

A importância atribuída à escolarização primária e o sentido que essa importância apresentava continuaram a orientar as atividades da Liga Nacionalista de São Paulo, durante a década de 20. A ligação entre os líderes dessa organização e os revolucionários de 1924 mostra até que ponto essa importância se transformava no entusiasmo pela escolarização, e como tal entusiasmo se metamorfoseava no principal instrumento para acelerar a história do país.

É neste cenário de uma urgência pela escolarização no país, que a literatura se lança a produzir as primeiras obras voltadas para crianças, pois parece haver uma relação entre a necessidade de escolarização e a ampliação da produção de obras para o público infantil e juvenil. Destacam Lajolo \& Zilberman (1985, p. 26) que:

Até a chegada de D. João VI, em 1808, o suporte editorial (e até mesmo tipográfico) necessário para o assentamento de um sistema literário era, mais do que precário, inexistente. Decorre muito tempo, até que tipografias, editoras, bibliotecas e livrarias tornem o livro um objeto não tão raro, ao menos nos centros urbanos mais importantes. 
No entanto, até final do século XIX, as obras que circulavam para o público infantil e juvenil compunham-se de traduções e adaptações de obras estrangeiras (Cf. LAJOLO E ZILBERMAN, 1985), o que despertará um sentimento em busca de uma literatura infantil nacional. Temos, portanto: "Neste clima de valorização da instrução e da escola, simultaneamente a uma produção literária variada, desponta a preocupação generalizada com a carência de material adequado de leitura para crianças brasileiras" (LAJOLO e ZILBERMAN, 1985, p. 28).

Para cumprir alguns propósitos, as obras infantis nacionais vão gradativamente ao início do século XX ocupando espaço na imprensa brasileira, pois (LAJOLO e ZILBERMAN, 1985, p. 28):

Intelectuais, jornalistas e professores arregaçaram as mangas e puseram mãos à obra; começaram a produzir livros infantis que tinham um endereço certo: o corpo discente das escolas igualmente reivindicadas como necessárias à consolidação do projeto de um Brasil moderno.

A expansão do sistema escolar viabilizará também a expansão dos negócios com os livros. Um dos exemplos desta relação poderá ser observado com a implantação dos Grupos Escolares em São Paulo e mais tarde sua difusão e implantação em outros Estados, constituídos por um modelo urbano organizado para atender grupos de alunos e "sujeitos a uma hierarquia administrativa e ao controle centralizado do Estado" (RAZZINI, 2004, p.2). A ampliação dos locais e do alunado faz crescer a necessidade de produção de livros que possam atender a essa demanda.

Essa ampliação do mercado se dará no campo do didático, embora possamos observar em Lajolo \& Zilberman (1985), que desde o século XIX já se adaptavam e traduziam obras para crianças no Brasil, no entanto havia uma necessidade de uma nacionalização da produção, o que se tornou 
fecundo com a expansão da escola. A exemplo desta tentativa, observamos que Monteiro Lobato publica seu primeiro livro em 1921, com o título de Narizinho Arrebitado (segundo livro de leitura para uso nas escolas primárias), que mostra a vinculação da produção de livros para crianças e o projeto de modernização do país, via escolarização.

Lajolo e Zilberman (1985, p. 46) explicam que "no princípio, Narizinho Arrebitado repetiu o sucesso de vendas de Saudade, de Tales de Andrade, sendo, ao mesmo tempo, adotado nas escolas públicas do Estado de São Paulo". No entanto, as obras nacionais para crianças não proliferam imediatamente. Há que se considerar (LAJOLO e ZILBERMAN, 1985, p. 46):

Na década de 20, destacam-se, dentre as criações de autores nacionais, quase que solitárias, as obras de Lobato. Suas raras companhias foram: as histórias de Tales de Andrade, publicadas na Coleção Encanto e Verdade, da Melhoramentos; e o livro de Gondim da Fonseca, O reino das maravilhas (1926) que, editado no conjunto da Biblioteca Quaresma, prolonga, neste período, certos traços da fase anterior, dependente, como se viu, das adaptações dos contos tradicionais.

Como podemos observar, no caso da primeira obra de Lobato, os livros para crianças parecem ter destino certo: as escolas. Não sem razão, Razzini (2004) vai apresentar estudos sobre a relação entre a expansão da escola pública em São Paulo e a expansão da livraria Francisco Alves:

A expansão da escola pública primária em São Paulo, encetada logo após a Proclamação da República, viria acelerar o desenvolvimento do mercado editorial e ampliar o mercado de trabalho, envolvendo professores, artistas, editores e técnicos da escrita, ilustração e produção de livros didáticos (RAZZINI, 2004, p. 1). 
Rompendo com a tradição das adaptações estrangeiras, o país, em vários campos clama por um nacionalismo. Mudanças pedagógicas, entre elas a difusão do método intuitivo:

Em voga no Brasil desde a última década do império, apoiado, por exemplo, por Rui Barbosa, tanto nos seus pareceres sobre a Reforma do Ensino Primário (1883), quanto na tradução e adaptação do manual de Norman Alison Calkins, Primeiras lições de coisas, (1886) (RAZZINI, 2004, p. 3).

As adaptações de manuais e outros materiais para uso das escolas primárias também retratam o momento vivido pelo país de necessidade de modernização, de "progresso". A análise do método intuitivo, através do manual Lições de coisas, onde são levantadas e analisadas diferentes concepções de progresso vinculadas ao projeto modernizador da sociedade. Além disso, a autora considera que:

O conteúdo ensinado com o nome de lições de coisas veicula uma valorização do progresso científico e das aplicações a ele relacionadas. São acrescentadas ao programa escolar áreas de conhecimento relativas às atividades produtivas, tais como as ciências físicas e a geometria e suas aplicações na construção de máquinas e produtos (VALDEMARIM, 2000, p. 84),

A idéia de que o país encontrava-se atrasado em relação ao mundo e de que havia uma necessidade de se entrar na rota do progresso, garante ao período mencionado a necessidade de importação de modelos. Há uma incorporação de idéias positivistas no campo da educação brasileira, através das idéias de alguns intelectuais, impregnadas pela necessidade de ordem, que "prometia" alcançar "com certeza o progresso". Valdemarim (2000) reflete, no entanto, que diferentes concepções de progresso estão presentes neste momento, sobre os quais não nos aprofundaremos neste texto. 
O progresso tão almejado só poderia ser alcançado, a partir da educação, sendo a via de maior alcance a escolarização. Há uma busca, ou ainda, uma reação contra a doutrina confessional religiosa e a necessidade de um saber científico positivo, prático e objetivo. Além disso, sendo um dos princípios do positivismo brasileiro a ordem, os atos da vida deveriam ser regulados e a liberdade moral reprimida, revelando uma educação fortemente disciplinadora.

Sobre esses aspectos, uma das questões importantes da divulgação do método intuitivo é que "junto com a observação e a experiência, o método intuitivo privilegiava a aprendizagem através da ilustração e do desenho" (RAZZINI, 2004, p. 4). Essa questão nos remete a importância que as ilustrações tomam nos livros a partir de um determinado período, pois ao considerar que "a adoção do método intuitivo e o uso da imagem só foi possível graças ao avanço das técnicas de impressão e das técnicas de fabricação de papéis, em curso desde a metade do século XIX, que baratearam o custo do material didático impresso" (RAZZINI, 2004, p. 4), observamos a correlação entre escolarização, mercado de livros, leitura, literatura, entre outras coisas.

É assim, que neste contexto de "expansão", que o país constrói condições para a expansão do mercado livreiro no país. No caso da escola pública primária, Razzini (2004, p. 5) destaca sua expressão por meio da reorganização dos espaços e do tempo escolar, pois:

Tal ponto de inflexão da escola primária exigia não só prédios e móveis específicos, mas também o uso de novos materiais didático-pedagógicos como livros, cadernos e impressos iconográficos (mapas e cartazes). Além disso, a nova organização do espaço e do tempo imposta pelo modelo dos Grupos Escolares contribuiu para a afirmação do ensino simultâneo e para a uniformização e seriação dos 
conteúdos, o que passou a exigir uma variedade muito maior de livros e de outros materiais adaptados ao ensino graduado de todas as matérias do currículo.

Assim, o mercado livreiro no país, especialmente quando da expansão da escolarização cresce e amplia o espaço para as obras didáticas. Dentre as Editoras podemos destacar a Editora Francisco Alves, a Laemmert e a Garnier. A primeira expandirá consideravelmente a partir da expansão da escola no país"

Neste período republicano, nota-se que a prosperidade da Livraria Francisco Alves acompanhou a expansão da escola pública primária, pois, se de 1854 a 1889 ela havia publicado apenas 75 títulos (sendo 62 dirigidos ao ensino), de 1890 a 1919 ela lançou 550 títulos, dos quais 307 eram didáticos (RAZZINI, 2004, p. 9).

Outros trabalhos de pesquisadores brasileiros vão destacar a relação entre a literatura infantil e juvenil e escola e sua relação com a escolarização no Brasil. Lajolo (2006, p. 66) nos lembra que "na tradição brasileira, literatura infantil e escola mantiveram sempre uma relação de dependência mútua".

Essa parceria tão antiga entre a literatura para crianças amplia não só o mercado como as possibilidades de alguns brasileiros iniciarem a publicação de suas obras destinadas a este público. Sobre este, iremos nos deter sobre: Monteiro Lobato.

\section{Considerações finais: os livros para crianças, autores e editores- Monteiro Lobato}

As primeiras obras destinadas ao público infantil eram traduções e adaptações estrangeiras, dentre elas, textos de autores franceses e outros. 
Como já evidenciamos anteriormente, com os ideais republicanos de progresso e o nacionalismo, há uma necessidade de nacionalização das obras destinadas ao público infantil e o que Lajolo e Zilberman (1985, p. 23) chamam de a "formação de um novo gênero".

Se a literatura infantil européia teve seu início às vésperas do século XVIII, quando em 1697, Charles Perrault publicou os célebres Contos da Mamãe Gansa, a literatura infantil brasileira só veio surgir muito tempo depois, quase no século $\mathrm{XX}$, muito embora, ao longo do século XIX reponte, registrada aqui e ali, a notícia do aparecimento de uma ou outra obra destinada a crianças (LAJOLO e ZILBERMAN, 1985, p. 23).

Interessado neste mercado promissor, Monteiro Lobato, autor e editor buscará neste mercado a difusão de suas obras. No entanto, é importante considerar que antes mesmo de Lobato se aventurar pelos caminhos da produção ao público infantil, nossas adaptações eram fortemente influenciadas:

Muito ligado à cultura francesa em todos os aspectos da vida social, o Brasil, - em geral-e a capital em particular - vivia, na virada do século XIX para o século XX, um momento de idolatria da cidade de Paris, considerada a capital da modernidade e da civilização ocidental", sendo que livros de alguns autores brasileiros eram impressos em Paris (FEIJÓ, 2005, p. 454).

As editoras que irão se destacar no momento histórico em questão, se encontravam no Rio de Janeiro, dentre elas as mais importantes eram a Garnier e os irmãos Laemmert:

Eram, na verdade, duas casas publicadoras (editoras) que, tendo iniciado suas atividades em meados do século XIX, representavam o que havia de mais nobre no setor editorial brasileiro. Foi com elas que a 
publicação de livros separou-se da edição de jornais. Os livreiros-editores estrangeiros, como os irmãos Garnier e os irmãos Laemmert, foram às figuras dominantes do nosso humilde mercado editorial até o início da era Monteiro Lobato (FEIJÓ, 2005, p. 454).

O mercado editorial brasileiro, no entanto passou por inúmeras dificuldades, pois "a fabricação de papel era incipiente, equipamentos gráficos adequados praticamente inexistiam e a distribuição dependia de um número muito reduzido de livrarias. Tínhamos livreiros-editores, mas não tínhamos indústria editorial” (FEIJÓ, 2005, p.455).

Ao final do século XIX, há que se destacar o papel do imigrante Francisco Alves, o primeiro a investir em livros para a escola primária, através da Livraria Francisco Alves, sobre o qual observamos aspectos de sua atuação, na primeira parte deste trabalho em investigação da pesquisadora Márcia Razzini (2004).

Em 1910 foi publicado pela Editora Francisco Alves, o livro Através do Brasil de Olavo Bilac e Manoel Bonfim, que para Feijó (2005, p. 457): "Era um livro barato, sem luxo, e, sobretudo, de leitura fácil e envolvente. Sua circulação tinha endereço certo: a escola. Era simultaneamente, um projeto educacional sincero de seus autores e um empreendimento comercial de grande potencial".

Apesar da tentativa de nacionalização dos livros, os editores ainda não contavam com condições para publicação dos livros, que eram impressos em Paris. Um exemplo pode ser observado pelo livro Através do Brasil, que de conteúdo "legitimamente brasileiro" (FEIJÓ, 2005, p. 458), fora impresso em Paris. 
A partir de 1918, Monteiro Lobato inicia suas atividades no papel de editor, mais tarde publica seus próprios trabalhos destinados às crianças, pois (FEIJÓ, 2005, p. 460):

Em 1918, o escritor Monteiro Lobato comprou a empresa revista do Brasil. Começava sua grande aventura editorial, que continuava em suas empresas do ramo: a Monteiro Lobato \& Cia., depois a Companhia Editora Nacional e finalmente a Brasiliense.

Mais tarde com o sucesso de Narizinho Arrebitado, o autor e editor seria reconhecido como pioneiro na publicação de obras para crianças.

Feito este pequeno vôo sobre Monteiro Lobato, consideramos, finalmente que evidenciamos uma relação muito propícia para o surgimento de trabalhos voltados para as crianças e a expansão da "necessidade" criada para a escolarização da população, evidenciada através da importação e incorporações de idéias no campo educacional, vinculado aos ideais republicanos de diferentes grupos, expressos no início da República, que influenciaram sobremaneira toda a produção de bens, dentre os quais tratamos neste texto especialmente do livro.

\section{Referências bibliográficas:}

CHARTIER, Anne Marie; HEBRARD, Jean (1995). Discursos sobre a leitura 1880-1980. São Paulo: Editora Ática.

FEIJÓ, Mário (2005). As adaptações de clássicos para crianças na primeira metade do século $\mathrm{XX}$ e a nacionalização do livro escolar no Brasil. In: ABREU, Márcia; SCHAPOCHNIK, Nelson (Orgs.). Cultura letrada no Brasil: objetos e práticas, Campinas, São Paulo: Mercado das letras, ALB. 
HÉBRARD, Jean (1999). Três figuras de jovens leitores: alfabetização e escolarização do ponto de vista da história cultural. In: ABREU, Márcia (Org.). Leitura, história e história da leitura. Campinas-SP: Mercado das letras.

(1990). A escolarização dos saberes elementares na época moderna, Teoria e Educação, $\mathrm{n}^{\circ}$ 02, 1990, p. 65-110.

LAJOLO, Marisa; ZILBERMAN, Regina (1985). Literatura infantil brasileira: história e histórias. São Paulo: Ática.

Ática. (1996). A formação da leitura no Brasil. São Paulo: (2002). A leitura rareita: livro e leitura no Brasil. São Paulo: Ática.

São Paulo: Ática.

(2006). Do mundo da leitura para a leitura do mundo.

NAGLE, Jorge (2001). Educação e sociedade na Primeira República. Rio de Janeiro: DP \& A Editora.

RAZZINI, Márcia de Paula Gregório. A livraria Francisco Alves e a expansão da escola pública em São Paulo. In: I SEMINÁRIO BRASILEIRO SOBRE O LIVRO E HISTÓRIA EDUTORIAL. Rio de Janeiro, Anais.

SOUZA, Rosa Fátima de (2004). Lições da escola primária. SAVIANI, Dermeval et al (Orgs.) O legado educacional do "longo século XX" brasileiro. São Paulo: Editora Autores Associados.

VALDEMARIM, Vera Teresa (2000). Lições de coisas: concepção política e projeto modernizador para a sociedade. Cadernos Cedes, Campinas: ano XX, $\mathrm{n}^{\circ} 52$, novembro. 


\section{Autoras:}

Roseli Maria Rosa de Almeida

Mestranda do Programa de Pós-Graduação em Educação-Mestrado em Educação da Universidade Federal de Mato Grosso do Sul.

Contato: roselimariarosa@yahoo.com.br

$\mathrm{e}$

Ana Lucia Espíndola

Professora Doutora do Departamento de Educação da Universidade Federal de Mato Grosso do Sul - Campus de Três Lagoas.

Contato: anaespindola@uol.com.br

\section{Como citar este artigo:}

ALMEIDA, Roseli Maria Rosa de \& ESPÍNDOLA, Ana Lucia. Escolarização e leitura para crianças no Brasil no início da República. Revista ACOALFAplp: Acolhendo a Alfabetização nos Países de Língua portuguesa, São Paulo, ano 5, n. 9, 2010/ 2011. Disponível em: <http://www.acoalfaplp.net>. Publicado em: setembro de 2010 - março de 2011.

Recebido em março de 2009./ Aprovado em junho de 2009. 